Research Article

\title{
Analysis of the Response of Urban Water Consumption to Climatic Variables: Case Study of Khorramabad City in Iran
}

\author{
Omid Hamidi $\mathbb{D D}^{1}{ }^{1}$ Hamed Abbasi ${ }^{(D)}{ }^{2}$ and Hamid Mirhashemi ${ }^{2}{ }^{2}$ \\ ${ }^{1}$ Department of Science, Hamedan University of Technology, Hamedan 65155, Iran \\ ${ }^{2}$ Department of Geography, Lorestan University, Khorramabad, Iran \\ Correspondence should be addressed to Hamed Abbasi; abbasi.h@lu.ac.ir
}

Received 3 December 2020; Accepted 8 March 2021; Published 19 March 2021

Academic Editor: Nir Y. Krakauer

Copyright (C) 2021 Omid Hamidi et al. This is an open access article distributed under the Creative Commons Attribution License, which permits unrestricted use, distribution, and reproduction in any medium, provided the original work is properly cited.

Iran is located in a dry climate belt. Such conditions have made the supply of urban water resources one of the most fundamental management challenges. The amount of water consumed in a city is affected by the weather conditions greatly such that as the weather changes, the amount of water consumed changes as well. In this study, several models including zero-order Pearson's correlation coefficient, first-order Pearson's correlation, generalized additive model (GAM), generalized linear model (GLM), support vector machine (SVM-Nu), and simplex optimization algorithm were used in order to identify linear/nonlinear reactions of monthly water consumption to the individual and combined associations of meteorological variables (temperature, air pressure, and relative humidity) in Khorramabad city. Zero-order and first-order correlations showed that, by controlling the air temperature, the effect of pressure and relative humidity on changes in water consumption increase. On the other hand, both individual and combined GAM models showed the same result in the nonlinear response of water consumption to the changes in relative humidity and air pressure. The spline method also revealed that, by eliminating the effect of air temperature, the nonlinear reaction of water consumption to changes in pressure and relative humidity was increasing, and by eliminating the effects of the relative humidity and air pressure, the nonlinear reaction of water consumption to the air temperature was intensified. In general, by decreasing the air pressure and temperature, the amount of urban household water consumption decreases drastically. These conditions are generally provided by entering low-pressure systems.

\section{Introduction}

Climate affects many aspects of human life both directly and indirectly and plays an important role in determining the socioeconomic, cultural, and physiological functions of the community at any time. One of the most important determinants of human life is water so that its amount and pattern are influenced by the prevailing climate conditions. Although the absolute amount of water consumption mainly depends on population, technology level, culture of consumption, type of livelihood, and many other human parameters, it is evident that, given the relative stability of human factors, the occurrence of water consumption patterns depends highly on the monthly and seasonal frequencies of climatic variables. Therefore, the climate is assumed to be the most important factor in the medium- term changes of water consumption. Xenochristou and Kapelan [1] considered that the amount of water consumption is mainly affected by environmental and socioeconomic factors. In this regard, Brelsford and Abbott showed that the implementation of water policies in Las Vegas (USA), during a period from 1996 to 2007, led to a $53 \%$ decrease in water consumption in spite of a $63 \%$ increase of population growth [2]. In several studies including those of Zubaidi et al. [3-6], Falahi et al. [7], Ansari and Salehnia [8], and Praskievicz and Chang [9], the crucial role of meteorological variables in predicting water consumption has been emphasized. Studies have also shown that the response of urban water consumption is positive to the air temperature and is negative to the precipitation $[6,10]$. It has also been indicated that the intensity of water consumption response to the meteorological variables is a function of the 
climatic condition of the study site. Kenney et al. [11] showed that, in Colorado with semiarid climates, water consumption increased by 2 percent per one-degree increase in temperature and decreased by 4 percent per one-inch increase of rainfall. Balling and Gober [12] conducted a study in Phoenix, Arizona, with a warm and dry climate and showed that a $1 \%$ increase in precipitation resulted in a $0.001 \%$ decrease in water consumption, whereas a $1 \%$ increase in evaporation led to a $0.464 \%$ increase in water consumption. Polebitski conducted a study in Seattle, with humid and temperate climate, and showed that by a 10 percent increase in the average maximum temperature during July and August, the water consumption increased by 10 percent, while a 10 percent increase in temperature during September and October led to a $4.5 \%$ increase in water consumption. Moreover, a $10 \%$ increase in total precipitation during May and June led to a $2.5 \%$ decrease in total water consumption [13].

The intensity of the water consumption response to meteorological variables for a given location varies during different seasons. Maidment and Miaou showed that the response of water consumption to precipitation depends on the frequency and the amount of precipitation, and the response of water consumption to the air temperature is nonlinear [14]. By studying the reactions of water to temperature changes in Stone City, Texas, Maidment et al. found that the intensity of water consumption has a great change in a temperature above $28^{\circ} \mathrm{C}$ (it is 6 times greater compared to the temperatures between $13^{\circ} \mathrm{C}$ and $28^{\circ} \mathrm{C}$ ) [15]. Due to the higher intensity of water consumption reaction in early summer than in late summer, Chang et al. concluded that other variables such as relative humidity or evaporation may be considered as climatic factors that can affect water consumption in late summer [16].

As is known, water consumption is affected both by humanized factors with random nature and climatic elements with a dynamic nature, which leads to the complexity of the time-series signal of water consumption. Therefore, identifying its response pattern to independent variables and providing predictive models can be a part of research priorities in this area for each location. Therefore, the present study was conducted to identify the linear and nonlinear reactions (responses) of Khorramabad's monthly water consumption to climatic variables. In this regard, by applying advanced modeling techniques like GAM and simplex optimization algorithm, it has been tried to find the crude/net response of water consumption relative to changes to each meteorological variable, as well as to investigate the response of water consumption in different climatic conditions.

\section{Materials and Methods}

2.1. Data and Study Area. This study was conducted in Khorramabad city, located in $21^{\circ} 48^{\prime} \mathrm{E}$ and $32^{\circ} 30^{\prime} \mathrm{N}$, with an altitude of 1170 meters in the Zagros Mountains in western Iran (in Lorestan province). The meteorological data, including temperature (degree Celsius), relative humidity (percentage), and air pressure (hectopascal), as well as monthly water consumption from March 2012 to March 2018 were used. To fit the linear relationship between the three meteorological variables and water consumption, a zero-order Pearson correlation coefficient was used. Also, one-order Pearson's correlation coefficient was used to obtain the net effects of temperature, relative humidity, and pressure on water consumption.

Zero-order correlation calculates the correlation between two variables without controlling other variables. Partial correlation indicates the correlation between two variables, by controlling the effect of other variables, so that if the effect of one variable is controlled, it is called one- or first-order correlation. In another step, a generalized additive model (GAM) was used to identify the nonlinear response of water consumption to the individual and combined changes in temperature, relative humidity, and air pressure. Finally, considering temperature, relative humidity, and air pressure as independent variables and water consumption as the response variable, linear and nonlinear models of water consumption were constructed using generalized linear model (GLM) and support vector machine (SVM-Nu), respectively. Then, to explore the conditions in which the three meteorological variables act synergistically with each other or counteracted and their effect on the water consumption, we used simplex optimization method for the GLM and SVM-Nu models.

2.2. Generalized Linear Model (GLM). GLM is a parametric model that is an extension of linear models. In this model, a formula is presented to show the relationship between the independent and dependent variables as follows [17]:

$$
g(\mu)=a+\sum \beta_{j} x_{j}
$$

where $g$ is the link function of the exponential family.

2.3. Generalized Additive Model (GAM). Generalized additive model (GAM) is a nonparametric statistical model which is an extension of the GLMs [18]. In these models, unlike parametric models, the relationship between independent and dependent variables is allowed to be nonlinear. In these models, it is assumed that the response variable has a distribution that belongs to the exponential distribution family and the mean $\left(\mu=E\left(Y \mid X_{1}, \ldots, X_{p}\right)\right)$ is connected to the independent variables $\left(X_{j}\right)$ through a link function $(g)$. In fact, GAM extends the parametric form of the independent variables in the linear model to a nonparametric form [19], i.e.,

$$
g(\mu)=a+\sum_{j=1}^{p} f_{j}\left(X_{j}\right) .
$$

Here, it is assumed that $f_{j s}$ are unknown and smooth functions of independent variables $\left(X_{j}\right)$. Specifically, $f_{j}$ is estimated using the data by advanced smoothing techniques. These functions are additive, which means that the effect of each predictor can be tested separately [20]. This property 
TABLE 1: Zero-order and first-order correlations of meteorology variables to water consumption.

\begin{tabular}{lcccc}
\hline Variable & $\begin{array}{c}\text { Zero-order correlation } \\
\text { Water consumption }\end{array}$ & Control (temperature) & $\begin{array}{c}\text { First-order correlation } \\
\text { Control (air pressure) }\end{array}$ & Control (relative humidity) \\
\hline Temperature $\left({ }^{\circ} \mathrm{C}\right)$ & 0.57 & - & 0.62 & 0.43 \\
Air pressure $(\mathrm{hPa})$ & -0.34 & 0.44 & - & 0.11 \\
Relative humidity $(\%)$ & -0.47 & 0.23 & -0.36 & - \\
\hline
\end{tabular}

has led to identifying nonlinear relationships between variables in this model [21].

2.4. Support Vector Machine(SVM). Support vector machine was first developed by Vapnik and Chervonenkis as a set of algorithms based on statistical learning theory [18]. This method is a data-driven model working based on supervised learning that is used in classification and regression problems. In other words, it is a method for classification in the arbitrary feature space and thus a suitable method for prediction problems. This method is a classifier that attempts to create a hyperplane that maximizes the distance of each class from the hyperplane. The data that are closest to the hyperplane (called support vectors) are used to measure this distance [22]. In general, this method is an efficient learning system based on the conditional optimization theory that uses the structural minimization principle that leads to an overall optimal solution [23].

In the support vector regression, the following relationship is considered between the predictors $(X)$ and dependent variable $[21,24]$ :

$$
y=f(x)+\text { noise, } \quad \text { where } f(x)=W^{T} \cdot \phi(x)+b .
$$

Regression coefficients are obtained through optimizing a loss function as follows [21]:

$$
\frac{1}{2} w^{T} w-C\left(v \varepsilon+\frac{1}{N} \sum_{i=1}^{N}\left(\xi_{i}+\xi_{i}^{*}\right)\right)
$$

with the following constraints:

$$
\begin{aligned}
& \left(w^{T} \phi\left(x_{i}\right)+b\right)-y_{i} \leq \varepsilon+\xi_{i} \\
& y_{i}-\left(w^{T} \phi\left(x_{i}\right)+b\right) \leq \varepsilon+\xi_{i}^{*} \\
& \xi_{i}, \xi_{i}^{*} \geq 0 \\
& i=1, \ldots, N .
\end{aligned}
$$

In the above equations, $C>0$ is the capacity constant that determines the penalty when error occurs while model training, $w$ is the regression coefficients vector, and $\xi_{i}$ and $\xi_{i}^{*}$ are deficiency coefficients that determine the upper and lower limit of training error associated with the amount of the permissible error, $\varepsilon$. Moreover, $b$ is the constant (bias term), $N$ is the pattern of model training model, and $\phi(\phi=$ $\left.\exp \left(-\gamma\left|x_{i}-x_{j}\right|^{2}\right)\right)$ is the kernel function (which is utilized for prediction in high-complexity data by transferring data into a higher dimensional space). In this study, the radial basis kernel function was used, and its optimum parameters were obtained through cross validation [21].
2.5. Simplex Optimization Algorithm. A simplex algorithm [25] is a nongradient search technique working based on an optimization algorithm that is utilized to minimize an arbitrary function over a finite number of iterations. This algorithm works for any number of continuous variables and has no default assumptions about the function that should be optimized but the continuity. This algorithm starts by providing a solution and testing the solution's optimality. If the optimization is satisfactory, the algorithm stops; otherwise, the algorithm detects another optimal point by drawing a simplex. Then, the optimality of this solution is tested as well. This process is repeated until convergence [23]. In this study, the simplex algorithm was applied on the models produced by GLM and SVM, and the simulated water consumption of each model was optimized.

\section{Results and Discussion}

The results of Pearson's correlation between meteorological variables including air temperature, relative humidity, air pressure, and water consumption of urban households in Khorramabad are presented in Table 1. As seen, all three variables had a significant relationship with the amount of water consumption $(P<0.05)$. The air pressure and relative humidity had indirect relationship and the temperature had a direct relationship with the dependent variable. Our results were in concordance with those of Brentan et al. [26]. Since the warm season in Khorramabad is associated with a higher temperature and a lower air pressure and relative humidity compared with the cold season, it is evident that with the change of season from cold to warm, the amount of water consumption has an increasing trend, and then there is a seasonal cycle in the amount of water consumption in Khorramabad. According to the frequency analysis, such cycles with frequencies of 2.5 and 6 months were also observed in Khorramabad's water consumption (Figure 1). Many previous studies have also emphasized on the existence of monthly-seasonal cycles in the time series of water consumption.

As the correlation coefficients calculated in Table 1 are of degree zero and that the final effect of these meteorological variables on the amount of water consumption affects their interaction with each other, therefore, these coefficients do not imply a crude relationship with these variables. They show their general relationship with the response variable. Therefore, the overall relationship of each of the mentioned variables with the water consumption (Table 1), due to the influence of the other variables, is completely opposite to their pure relationship, and no proper understanding could be found about how the water consumption reacts to the changes in these variables. As in a study conducted by 


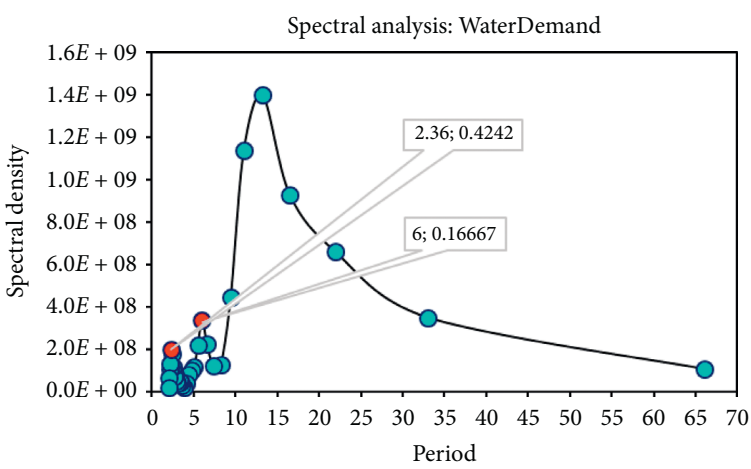

Figure 1: Periodogram of monthly water consumption time series in Khorramabad (2012-2018).

TABLE 2: The results of individual and composite GAM model on meteorological variables versus Khorramabad's water consumption.

\begin{tabular}{|c|c|c|c|c|c|c|}
\hline \multirow{2}{*}{ Variable } & \multicolumn{3}{|c|}{ Individual GAM model } & \multicolumn{3}{|c|}{ Composite GAM model } \\
\hline & Degree of freedom & Elements of model & $P$ value & Degree of freedom & Elements of model & $P$ value \\
\hline Air pressure $(\mathrm{hPa})$ & 3 & -0.0144 & $<0.001$ & 4 & 0.0253 & $<0.001$ \\
\hline Relative humidity (\%) & 3 & -0.004 & $<0.001$ & 3.99 & 0.0049 & $<0.001$ \\
\hline Temperature $\left({ }^{\circ} \mathrm{C}\right)$ & 2 & 0.108 & $<0.001$ & 4 & 0.039 & $<0.001$ \\
\hline
\end{tabular}

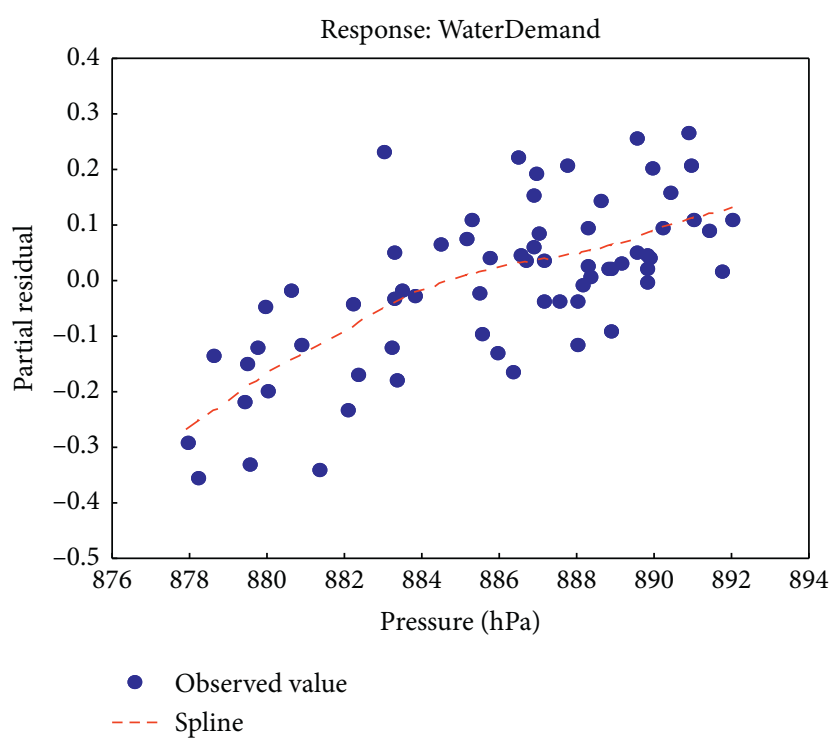

FIGURE 2: The combined response of the water consumption to pressure.

Souza et al. [27] for a region with warm and humid tropical climates (Brazil), the correlation coefficient of the relative humidity with the water consumption was positive, while its beta coefficient in multivariate regression was decreasing. This statistical difference indicates the involvement of the intermediate variables that control the relationship between relative humidity and water consumption.

On the other hand, understanding the processes and physical laws about the relationships between the meteorological variables are necessary in order to investigate the impact of these variables on the environmental phenomena. According to the full gas equation, it has been determined that the temperature and air pressure are in equilibrium mode, and in this thermodynamic equation, the air pressure is considered as a function of air temperature [28], i.e., the air pressure changes with air temperature or according to the saturated vapor pressure equation that expresses the final humidity holding capacity; relative humidity is also a direct function of the air temperature in addition to atmospheric humidity inventory [29].

With these arguments, and according to the temporal alignment of these variables, it seems that their relationships with the amount of water consumed in Khorramabad are greatly influenced by the inner relationship between them. Therefore, to identify the impact of each independent variable controlling for other variables, during a combined 


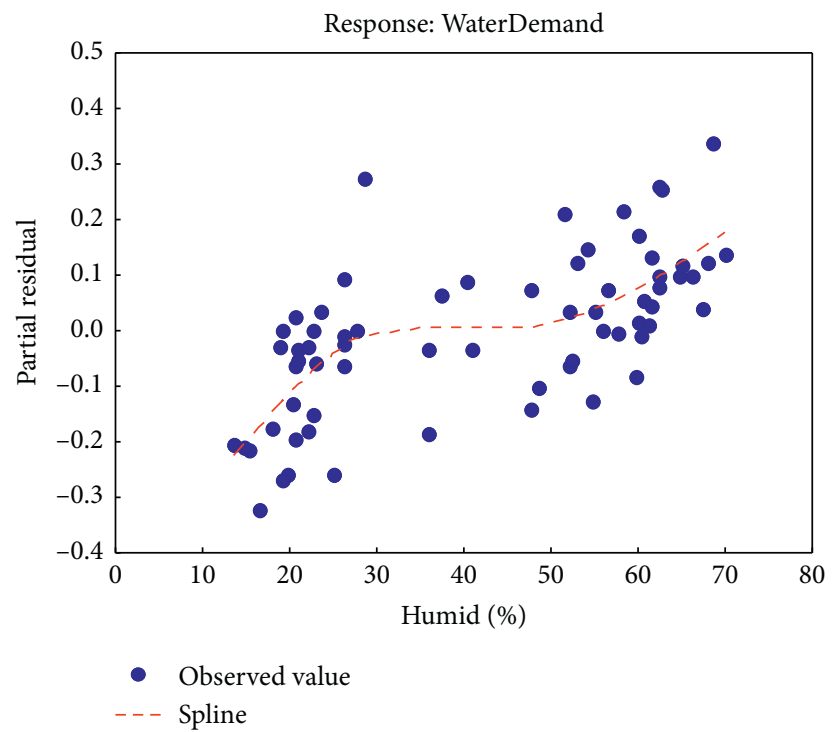

FIgURE 3: The combined response of the water consumption to relative humidity.

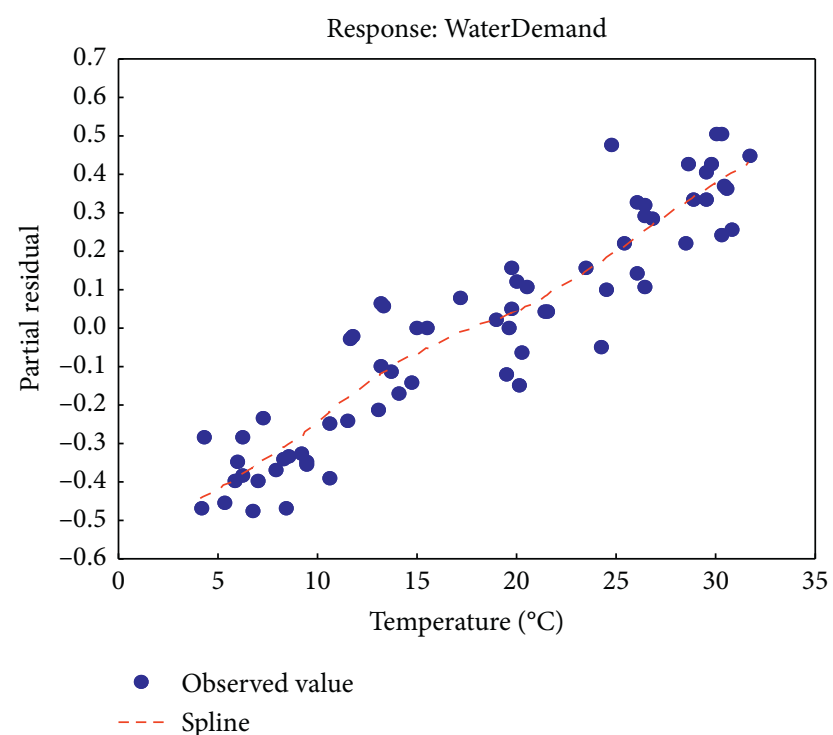

Figure 4: The combined response of the water consumption to temperature.

process, the differential correlation coefficients of each of the independent variables including air temperature, air pressure, and relative humidity were calculated. The results were presented in Table 1.

From these coefficients, it is evident that if the air pressure and relative humidity are constant, there is no significant change in the relationship between the air temperature and the water consumption of Khorramabad. However, after controlling for the air temperature, the relationships between the air pressure and the relative humidity with the water consumption were statistically significant. So, after controlling for the air temperature, the relationships of air pressure and relative humidity with the water consumed have changed to a reverse mode, and these two variables had a direct effect on the water consumption. The importance of this achievement is also highlighted by assessing the climatic status of Khorramabad city which is in the path of western and southwestern immigrants/transient systems [30].

At some points of a year, the climate of Khorramabad is subjected to changes due to the cold low-pressure and highpressure systems. In this way, by entering low-pressure air masses, the amount of water consumed has a much slower rate of decline, compared to the cold high-pressure masses. Because the temperature and pressure values in the former lead to a decrease in the amount of water consumed, in the latter, these two variables act against each other.

It is also noteworthy that such results are also the case for the mass entry of hot and low-pressure air as well as the dynamic warm high pressure, etc. In general, if the air masses have the same temperatures, similar changes should not be expected in the amount of water consumption in 


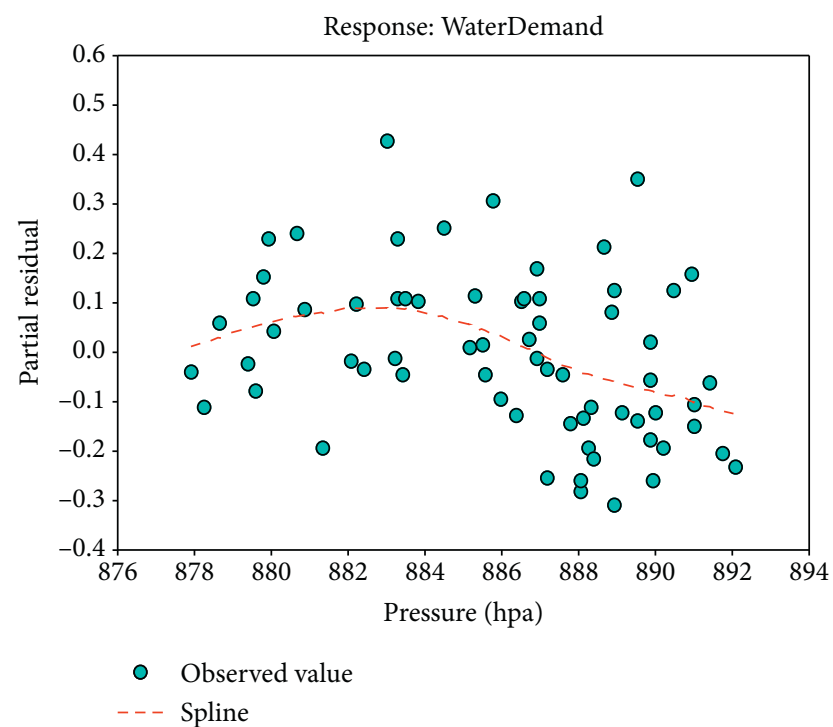

Figure 5: The individual response of the water consumption to pressure.

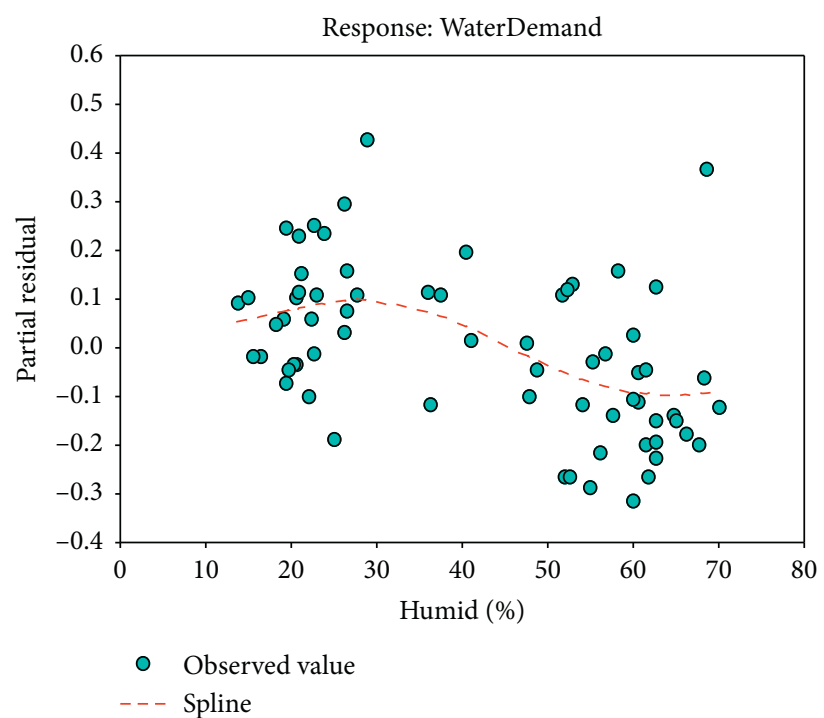

Figure 6: The individual response of the water consumption to relative humidity.

Khorramabad. This characteristic is contrary to the usual and standard air of Khorramabad, where the minimum air pressure in the hot season is based on high temperatures, and high pressure in the cold season is based on low temperatures so that, in May, the air pressure is 887 hectopascals based on a temperature of $9.6^{\circ} \mathrm{C}$ and in March, the air pressure is 887 hectopascals based on a temperature of $20^{\circ} \mathrm{C}$. However, these findings are related to the air temperature and relative humidity. Moreover, it was indicated that in addition to the direct effect, the air temperature affects the amount of water consumption indirectly through its relationship with the air pressure and relative humidity. In general, these processes have led to a nonlinear reaction of the Khorramabad water consumption to the changes of each of the meteorological variables if the effect of other variables does not maintain constant.
Both multivariate and univariate generalized additive model (GAM) were implemented to identify the nonlinear reaction of water consumption to the changes in the air temperature, relative humidity, and air pressure. The models were fitted based on Gauss, gamma, and Poisson's distribution using identity, inverse, and log link functions, and it was indicated that the Poisson GAM model using the log link function had the best efficiency. The results of this model were provided in Table 2. According to the results, the nonlinear effects of these meteorological variables were statistically significant $(P<0.01)$. The results of this nonlinear model were consistent with zero- and one-order correlation results.

In order to understand the nonlinear response of the water consumption against the variation of each variable by 


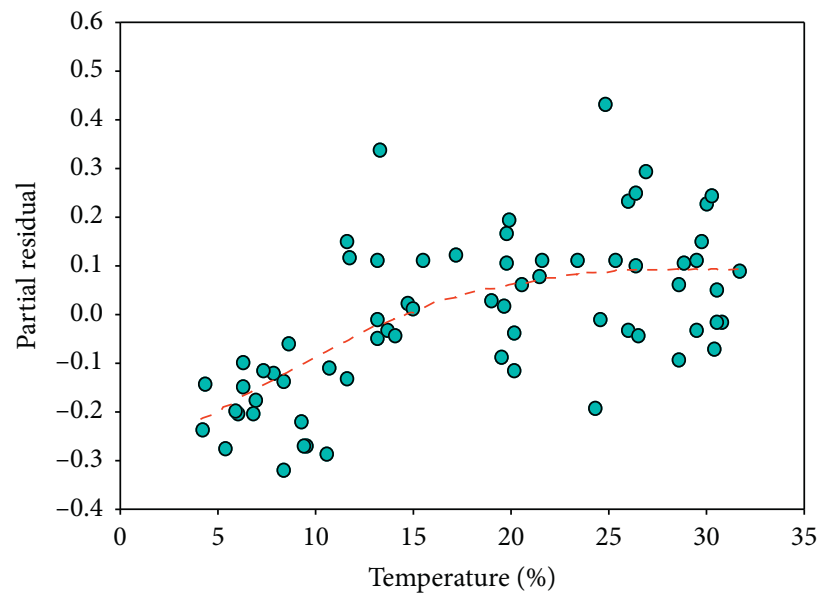

- Observed value -- - Spline

FIgURE 7: The individual response of the water consumption to temperature.

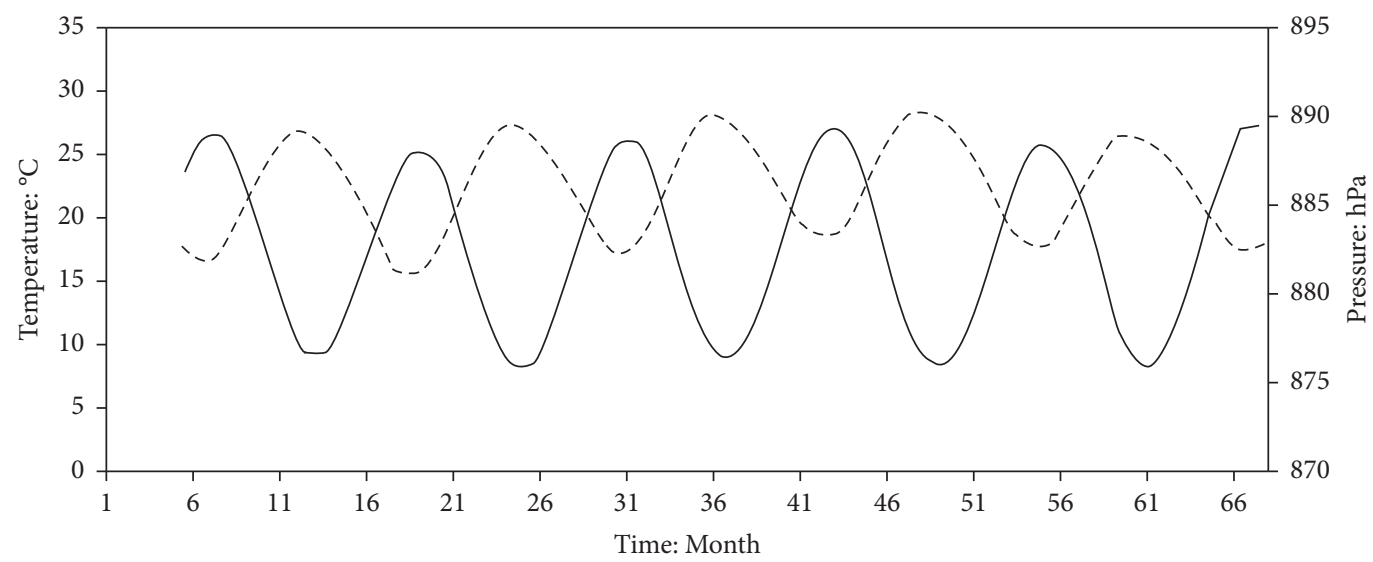

5 per.Mov. Avg.(temperature)

- - 5 per.Mov. Avg.(pressure)

(a)

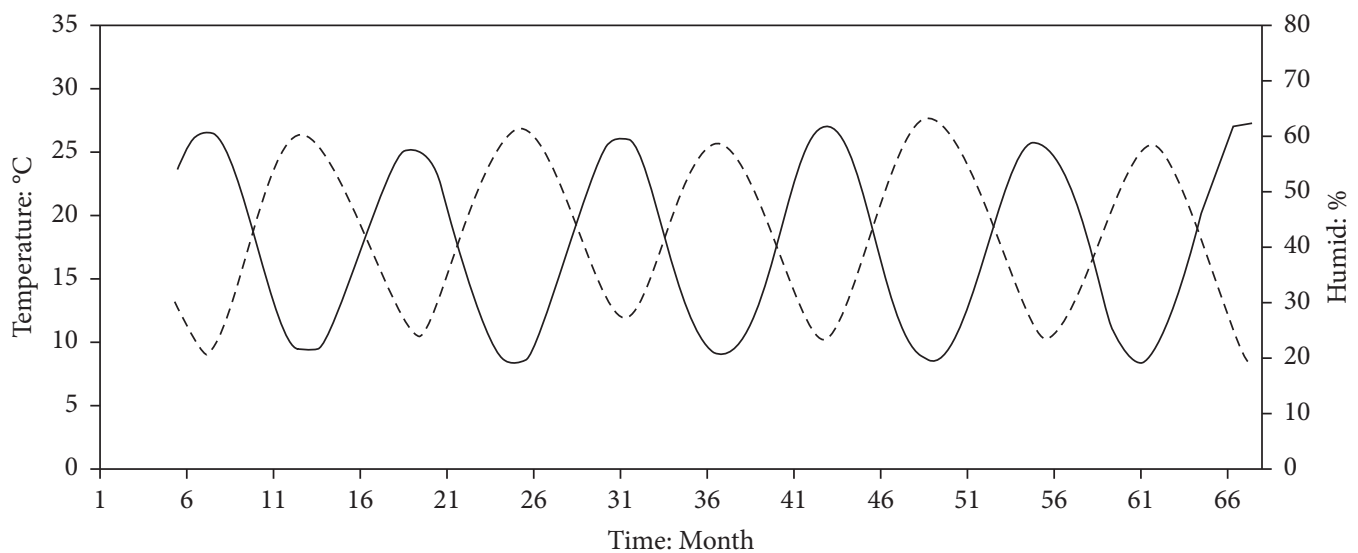

- 5 per.Mov. Avg.(temperature)

--5 per.Mov. Avg.(humid)

(b)

FIgURE 8: The 5-month moving average with a 5-month window: (a) temperature-pressure; (b): temperature-relative humidity. 
TABLE 3: The meteorology indices during summer, winter, and year.

\begin{tabular}{lccc}
\hline Season & Temperature $\left({ }^{\circ} \mathrm{C}\right)$ & Relative humidity $(\%)$ & Air pressure $(\mathrm{hPa})$ \\
\hline Winter & 8 & 60 & 892 \\
Summer & 29 & 20 & 880 \\
Annual & 18 & 41 & 886 \\
\hline
\end{tabular}

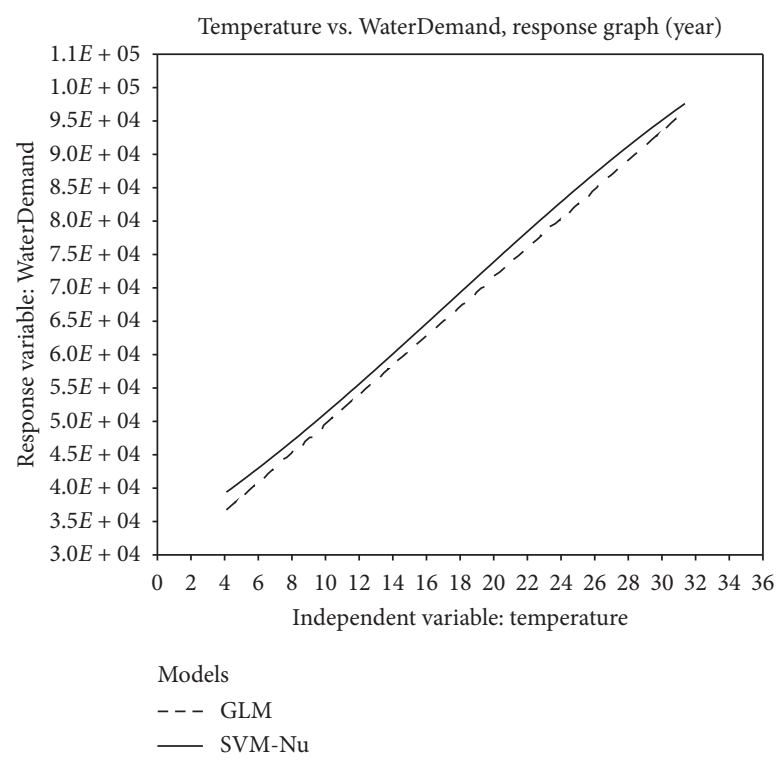

FIGURE 9: The reaction of water consumption to air temperature with annual conditions using GLM and SVM-Nu models.

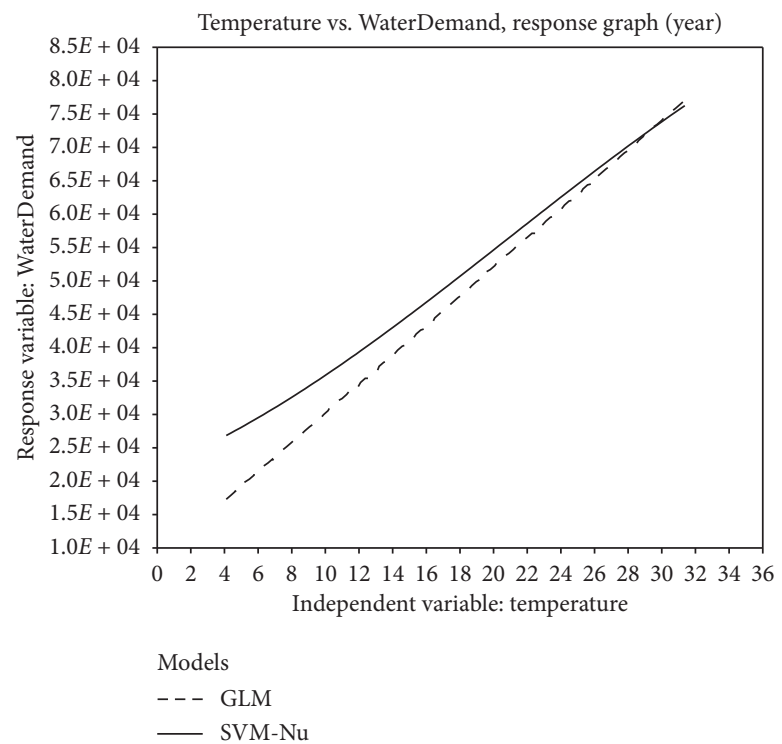

Figure 10: The reaction of water consumption to air temperature with summer conditions using GLM and SVM-Nu models.

eliminating the effects of other variables, the smoothing component diagram of the GAM model was plotted in single and combined mode (Figures 2-7). The evaluation of these figures showed that not only the intensity of the water consumption to the changes of each of these variables has changed to the hybrid mode, but also it had a significant variation in its response. In this way, in the individual mode, the air pressure varies increasingly and then decreasingly, while in the combined setting, it causes an increase in the water consumption more intensively. In general, in the individual mode, the amount of water consumption increases by increasing the pressure up to 884 hectopascals, and after this point, it decreases with the increase in the pressure. By removing the effects of other variables, the air pressure acts as 


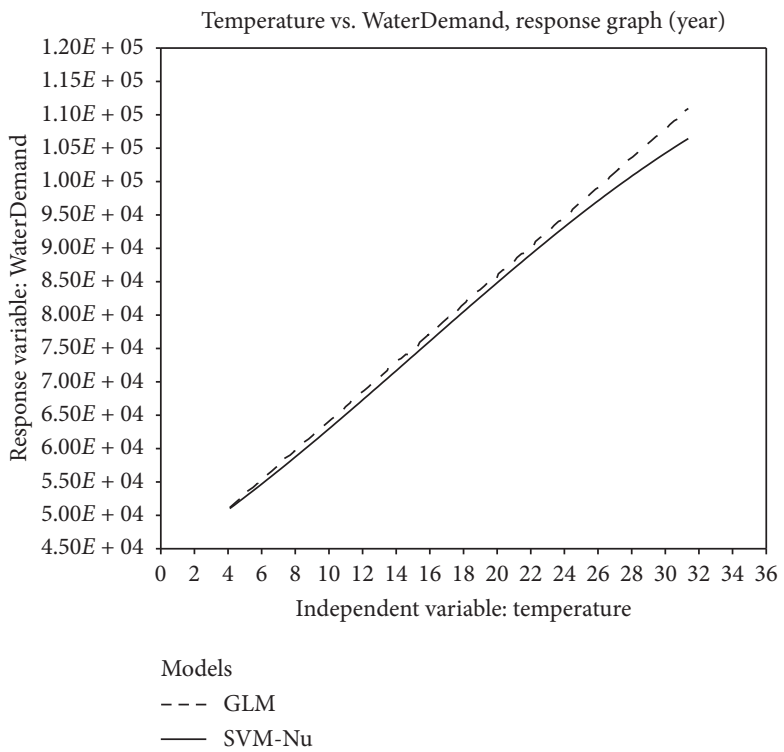

Figure 11: The reaction of water consumption to air temperature with winter conditions using GLM and SVM-Nu models.

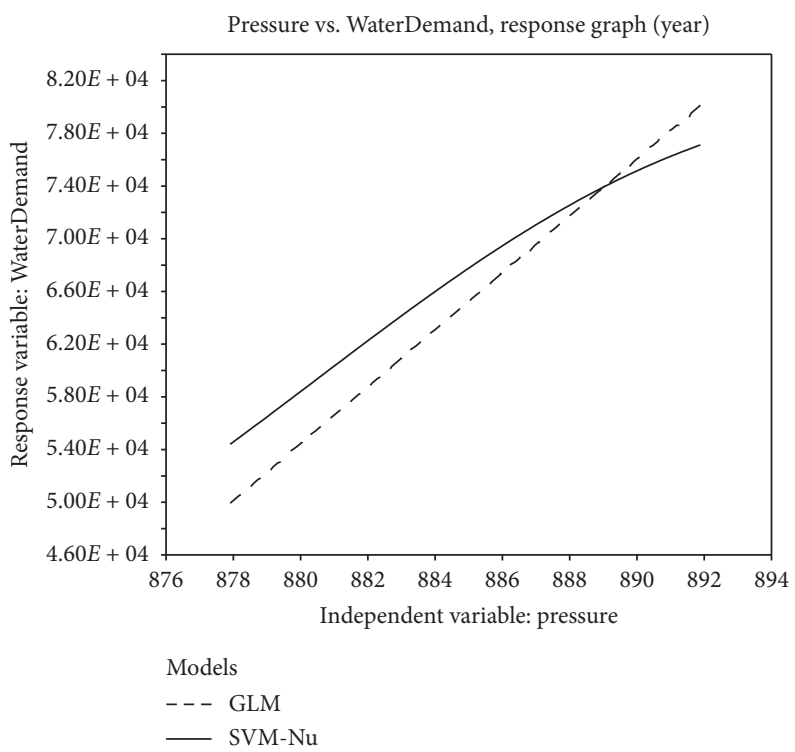

FIGURE 12: The reaction of water consumption to air pressure with annual conditions using GLM and SVM-Nu models.

a synergistic factor in the water consumption. The spline plots in these figures show that, in the case of removing the effect of other variables, the amount of water consumption increases dramatically with the increase in the temperature, while in the combined setting, the amount of the water consumption increases as the temperature increases up to $15^{\circ} \mathrm{C}$ (with the same intensity) and then it decreases gradually. Considering that the temperatures lower than $15^{\circ} \mathrm{C}$ occur during the cold season where the average air pressure and relative humidity are maximal compared to the warm season, it was indicated that the reaction of the consumption water to the variation of temperature in the cold season is greater compared to the warm season. On the other hand, Maidment and Miaou [14] introduced a threshold of $21^{\circ} \mathrm{C}$ in Texas, Florida, and Pennsylvania (United States). Akuoko provided a threshold of $15^{\circ} \mathrm{C}$ for Calgary (Canada) [29]. Sarker et al. introduced the threshold of $15.53^{\circ} \mathrm{C}$ for Melbourne (Australia) [30]. Maidment and Miaou [14] also revealed that the water consumption reacts to the $29^{\circ} \mathrm{C}$ to $32^{\circ} \mathrm{C}$ by three to five times greater compared with the temperatures lower than $29^{\circ} \mathrm{C}$. It is worth noting that these temperature thresholds are calculated individually through differentiation. Although these findings show the nonlinear response of water consumption to temperature variations, they are very important from the functional point of view. However, they do not exhibit the net effect of the temperature on consumption since no control 


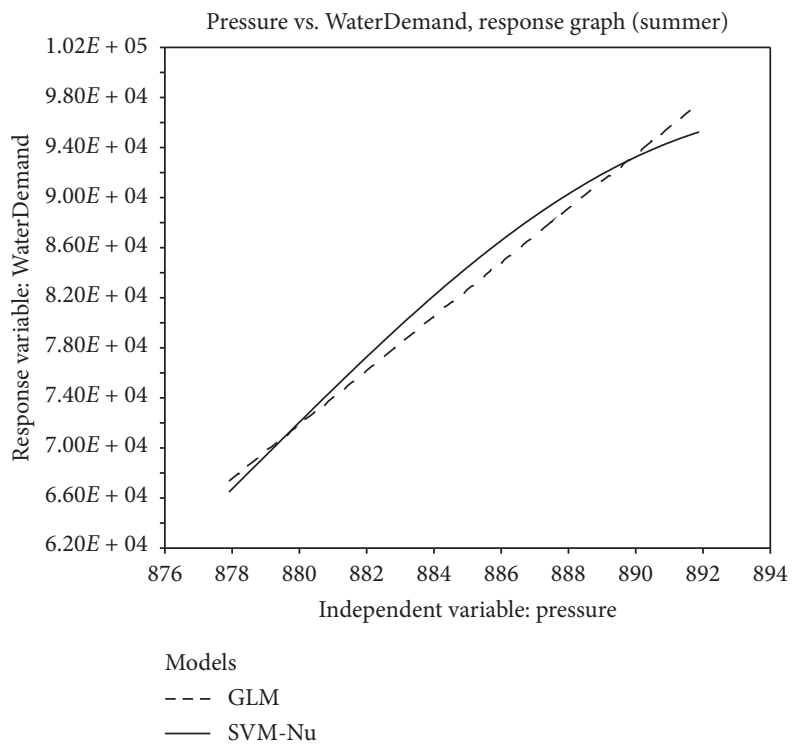

FIGURE 13: The reaction of water consumption to air pressure with summer conditions using GLM and SVM-Nu models.

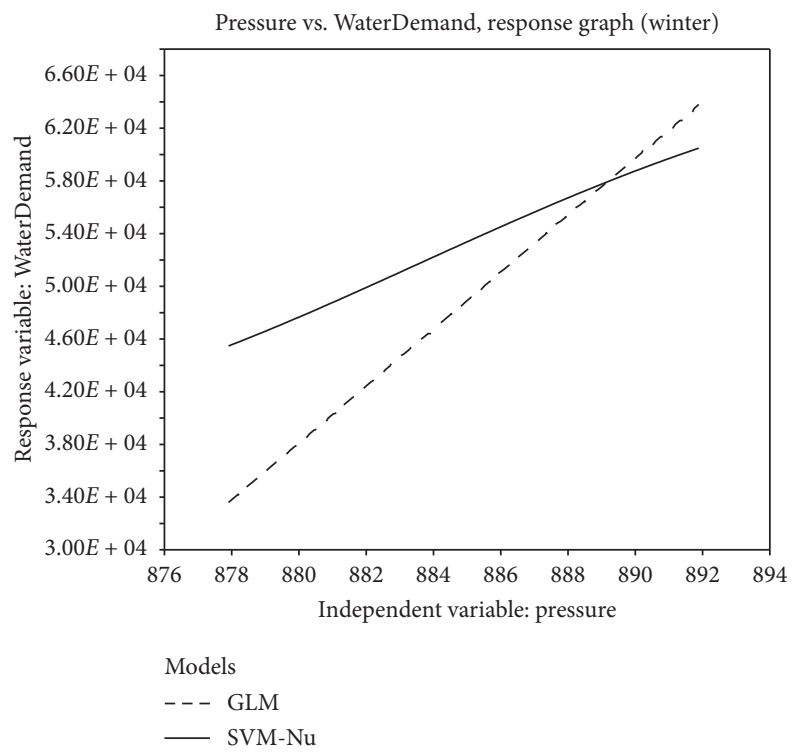

FIGURE 14: The reaction of water consumption to air pressure with winter conditions using GLM and SVM-Nu models.

over other variables has been taken and these thresholds have been achieved through individual implementation of the model.

The reaction of the water consumption to the relative humidity in the individual setting is in contrast to that of the combined setting. In the case of individual setting, the trend is increasing-decreasing, while in the combined setting, the intensity of water consumption in the lower and upper bounds is more severe than the median bound.

To make the results more understandable, a 5-month moving average time series analysis was carried out in the temperature, pressure, and relative humidity to remove the intraseasonal variations and to provide a clearer projection of seasonal variation (Figure 8). This is because the findings showed that, during the cold seasons, the western currents also play an important role in climate changes in Khorramabad.

The plots in Figures 8(a) and 8(b)) show that, by changing the season from winter to spring and summer, the temperature increases and air pressure decreases gradually. The spline component diagrams show an increasing net effect of air pressure, relative humidity, and temperature on the amount of the water consumption. So, in certain conditions, the combination of these three variables can synergistically affect the amount of water consumption. Meanwhile, the moving average plots show a negative trend in temperature against pressure and relative humidity. Although water consumption increases as the seasonal change happens from winter to summer, the negative confounding effect of temperature and relative humidity reduces the 


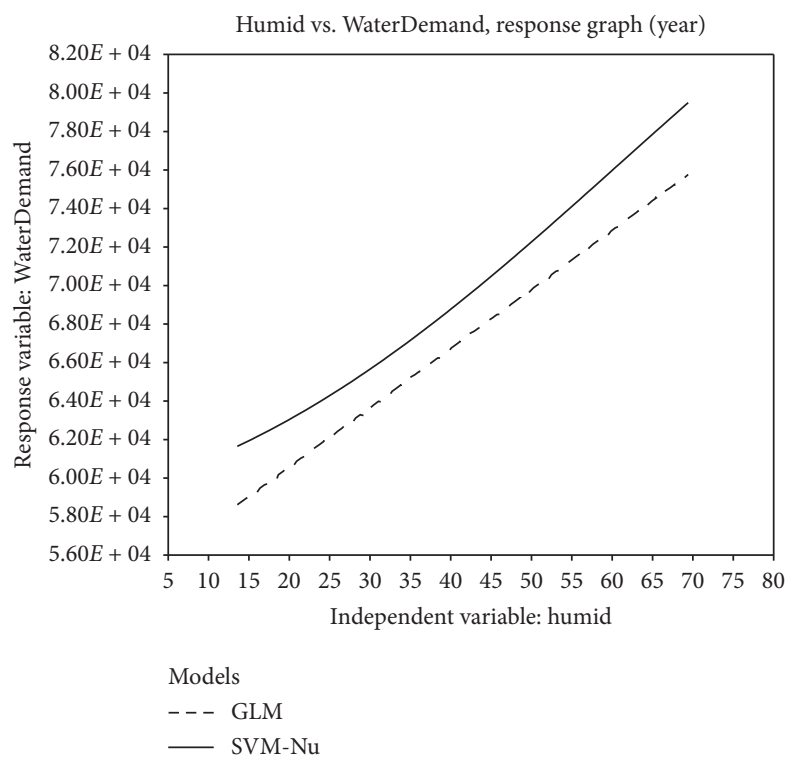

FIGURE 15: The reaction of water consumption to relative humidity with annual conditions using GLM and SVM-Nu models.

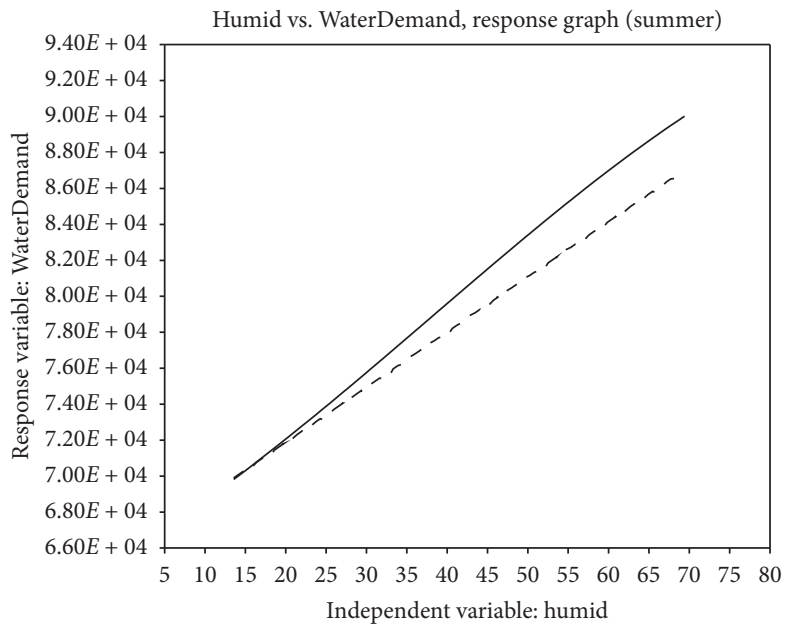

FIGURE 16: The reaction of water consumption to relative humidity with with summer conditions using GLM and SVM-Nu models.

impact of temperature on water consumption. In other words, the reaction of water consumption to temperature change in the cold seasons is more intense compared with the warm seasons. In warmer seasons, the relative humidity and air pressure affect the temperature as the water-reducing agents and thus reduce the effect of temperature changes on the increase of water consumption. As a result, the nonlinear reactions of the water consumption will be established against the meteorological variables, and therefore the linear correlation coefficient among these meteorological variables decreases with the amount of water consumption.

To evaluate the results more precisely, support vector machine (SVM) and generalized linear model (GLM) were used to assess the linear and nonlinear associations of temperature, pressure, and relative humidity with the amount of water consumption. Then, the simplex optimization algorithm was utilized to estimate the linear and nonlinear response of water consumption in winter and summer. The long-term averages of temperature, pressure, and relative humidity are shown in Table 3.

Assuming the air pressure and relative humidity to be fixed according to annual, summer, and winter mean values, the linear and nonlinear associations between annual, summer, and winter temperature changes and the water consumption were evaluated using the SVM and GLM. The results are shown in Figures 9-11. Moreover, the water consumption response to the air pressure change (Figures 12-14) and relative humidity (Figures 15-17) were assessed annually and during the summer and winter conditions using a simplex optimization algorithm. Regarding the results, the nonlinear reaction of the water consumption to the temperature change was more than its linear reaction. The nonlinear reaction in summer and winter is more severe and slower than the linear one. In 


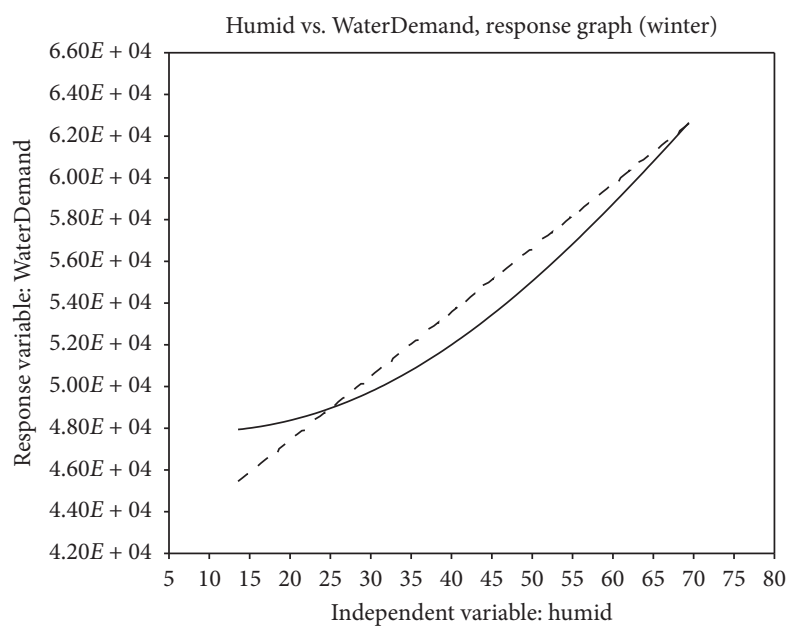

FIgURE 17: The reaction of water consumption to relative humidity with winter conditions by GLM and SVM-Nu models.

general, the intensity and the slope of the reaction to the temperature in the winter are more than those in the summer. These findings are due to the adjusting effect of the temperature on the water consumption. Regarding the plots, the response of the water consumption to a specific temperature in the winter settings of the air pressure and relative humidity is considerably higher compared with the summer settings. This result confirms the earlier implication that the entrance of the low-pressure cold air mass has an extra effect on reducing water consumption in winter. This is achieved through assessing the summer and winter response charts of the water used to the pressure changes.

The overall effect of relative humidity on water consumption was decreasing. However, by controlling the effect of other variables such as air temperature, it was indicated that the net effect of relative humidity on water consumption without the intervention of air temperature is increasing. Therefore, the negative effect of relative humidity on water consumption is due to the relationship between both water consumption and relative humidity with the air temperature so that, by controlling the effect of air temperature, this relationship is increasing. Therefore, in Figures 15-17, the effect of air temperature on the relationship between relative humidity and water consumption has been controlled, so the crude relationship between these two variables was increasing. Linear and nonlinear response plots of water consumption under annual, winter, and summer conditions show that the impact of air pressure on consumption is much lower than the summer and annual conditions. Comparing the nonlinear response curve in winter and summer indicated that the effect of a certain amount of air pressure on the water consumption in the summer is more severe than the winter condition. In contrast to the summer conditions, the nonlinear reaction of water consumption to the relative humidity in winter and annual conditions is higher than that of the linear reaction.

\section{Conclusions}

Weather plays a crucial role in the temporal pattern of urban water consumption. As with quarterly and monthly climate changes, monthly-seasonal frequencies are also appearing in the water consumption cycle. In this study, the effect of meteorological variables, including temperature, air pressure, and relative humidity, was investigated in Khorramabad city. Several linear and nonlinear methods were used, and the results of the simultaneous application of these methods revealed an important aspect in the influence of these factors on the water consumption.

The results obtained from the application of the GAM and the one-order correlation indicated that the linear and nonlinear effects of the temperature, relative humidity, and air pressure on the water consumption is increasing. The single-spline plots of GAM and zero-degree correlation showed reduced effects of relative humidity and air pressure. This might be due to their thermodynamic relations with air temperature. This is because the highest (lowest) temperatures in summer (winter) are based on the minimum (maximum) temperature and air pressure. Using the comparisons of the 4-month moving average, the trend of decreasing-increasing changes in the air pressure and the relative humidity is corresponding to the increasing-decreasing trend of temperature. Such a reverse time trend of these three variables has resulted in the neutralization of the intensity of the effect. The GAM single-spline plots showed that the intensity of the water consumption in the summer reduces due to the high temperatures and relative humidity.

To compute these associations, the linear and nonlinear relationship between the temperature, pressure, and relative humidity with the water consumption was firstly modeled using GLM and SVM-Nu. Then, the simplex optimization algorithm was used to assess the linear and nonlinear association of the water consumption with a specific variety 
while the effects of the other factors were assumed as fixed. Comparing the plots, the water consumption response to a specific pressure and relative humidity is more intensified in summers compared with winters, while it is reversed for its response to a specific temperature.

Regarding these findings and the fact that the climate in Khorramabad is not only affected by the local variables, but also by other factors such as western currents in some parts of year and because the thermodynamic-dynamic systems differ from the conventional climatic conditions of Khorramabad; therefore, under these conditions, the effect of the temperature, air pressure, and relative humidity on the water consumption is in the same direction and they have a tremendous cumulative effect on the amount of water consumed. This situation occurs from the late fall by the arrival of spring by dynamic cold flows.

\section{Data Availability}

The data used to support the findings of this study are available from the corresponding author upon request.

\section{Conflicts of Interest}

The authors declare that they have no conflicts of interest regarding the publication of this paper.

\section{References}

[1] M. Xenochristou and Z. Kapelan, "An ensemble stacked model with bias correction for improved water demand forecasting," Urban Water Journal, vol. 17, no. 3, pp. 212-223, 2020.

[2] C. Brelsford and J. K. Abbott, "Growing into water conservation? Decomposing the drivers of reduced water consumption in Las Vegas, NV," Ecological Economics, vol. 133, pp. 99-110, 2017.

[3] S. L. Zubaidi, I. H. Abdulkareem, K. S. Hashim et al., "Hybridised artificial neural network model with slime mould algorithm: a novel methodology for prediction of urban stochastic water demand," Water, vol. 12, no. 10, p. 2692, 2020.

[4] S. L. Zubaidi, H. Al-Bugharbee, Y. R. Muhsen, K. Hashim, R. M. Alkhaddar, and W. H. Hmeesh, "The prediction of municipal water demand in Iraq: a case study of Baghdad governorate," in Proceedings of the 2019 12th International Conference on Developments in eSystems Engineering (DeSE), IEEE, Kazan, Russia, October 2019.

[5] S. L. Zubaidi, K. Hashim, S. Ethaib, N. S. S. Al-Bdairi, H. AlBugharbee, and S. K. Gharghan, "A novel methodology to predict monthly municipal water demand based on weather variables scenario," Journal of King Saud University, 2020.

[6] S. L. Zubaidi, S. Ortega-Martorell, P. Kot et al., "A method for predicting long-term municipal water demands under climate change," Water Resources Management, vol. 34, no. 3, pp. 1265-1279, 2020.

[7] M. A. Falahi, H. Ansari, and S. Moghaddas, "Evaluating effective factors on household water consumption and forecasting its demand: panel data approach," Water Waste Journal, vol. 23, no. 4, pp. 78-87, 2012.
[8] H. Ansari and N. Salehnia, "Evaluating efficient parameters on municipal drinking water using GAMA test technique," Journal of Water and Wastewater, vol. 1, pp. 1-14, 2014.

[9] S. Praskievicz and H. Chang, "Identifying the relationships between urban water consumption and weather variables in Seoul, Korea," Physical Geography, vol. 30, no. 4, pp. 324-337, 2009.

[10] P. Huntra and T. C. Keener, "Evaluating the impact of meteorological factors on water demand in the Las Vegas Valley using time-series analysis: 1990-2014," ISPRS International Journal of Geo-Information, vol. 6, no. 8, p. 249, 2017.

[11] D. S. Kenney, C. Goemans, R. Klein, J. Lowrey, and K. Reidy, "Residential water demand management: lessons from aurora, Colorado1," JAWRA Journal of the American Water Resources Association, vol. 44, no. 1, pp. 192-207, 2008.

[12] R. C. Balling Jr. and P. Gober, "Climate variability and residential water use in the city of Phoenix, Arizona," Journal of Applied Meteorology and Climatology, vol. 46, no. 7, pp. 1130-1137, 2007.

[13] A. S. Polebitski and R. N. Palmer, "Seasonal residential water demand forecasting for census tracts," Journal of Water Resources Planning and Management, vol. 136, no. 1, pp. 27-36, 2010.

[14] D. R. Maidment and S.-P. Miaou, "Daily water use in nine cities," Water Resources Research, vol. 22, no. 6, pp. 845-851, 1986.

[15] D. R. Maidment, S.-P. Miaou, and M. M. Crawford, “Transfer function models of daily urban water use," Water Resources Research, vol. 21, no. 4, pp. 425-432, 1985.

[16] H. Chang, S. Praskievicz, and H. Parandvash, "Sensitivity of urban water consumption to weather and climate variability at multiple temporal scales: the case of Portland, Oregon," International Journal of Geospatial and Environmental Research, vol. 1, no. 1, p. 7, 2014.

[17] D. Lee and S. Derrible, "Predicting residential water demand with machine-based statistical learning," Journal of Water Resources Planning and Management, vol. 146, no. 1, Article ID 04019067, 2020.

[18] V. N. Vapnik and A. Y. Chervonenkis, "On the uniform convergence of relative frequencies of events to their probabilities," in Measures of Complexity, pp. 11-30, Springer, Berlin, Germany, 2015.

[19] N. A. Barton, T. S. Farewell, and S. H. Hallett, "Using generalized additive models to investigate the environmental effects on pipe failure in clean water networks," Npj Clean Water, vol. 3, no. 1, pp. 1-12, 2020.

[20] T. Hastie and R. Tibshirani, "Non-parametric logistic and proportional odds regression," Applied Statistics, vol. 36, no. 3, pp. 260-276, 1987.

[21] H. Lu, J. Matthews, and S. Han, "A hybrid model for monthly water demand prediction: a case study of Austin, Texas," AWWA Water Science, vol. 2, no. 2, p. e1175, 2020.

[22] V. Vapnik, The Nature of Statistical Learning Theory, Springer Science \& Business Media, Berlin, Germany, 2013.

[23] N. Cristianini and J. Shawe-Taylor, An Introduction to Support Vector Machines and Other Kernel-Based Learning Methods, Cambridge University Press, Cambridge, UK, 2000.

[24] L. Tapak, O. Hamidi, P. Amini, and J. Poorolajal, "Prediction of kidney graft rejection using artificial neural network," Healthcare Informatics Research, vol. 23, no. 4, p. 277, 2017.

[25] A. Bouach and S. Benmamar, "Examining the effect of water demand variation on optimization: the case for a genetic algorithm," International Journal of Energy and Water Resources, vol. 5, pp. 95-99, 2021. 
[26] B. M. Brentan, G. Meirelles, M. Herrera, E. Luvizotto, and J. Izquierdo, "Correlation analysis of water demand and predictive variables for short-term forecasting models," Mathematical Problems in Engineering, vol. 2017, 2017.

[27] A. d. Souza, F. Aristone, I. Sabbah, D. A. d. Silva Santos, A. P. d. Souza Lima, and G. Lima, "Climatic variations and consumption of urban water," Atmospheric and Climate Sciences, vol. 5, no. 3, p. 292, 2015.

[28] A. A. Tsonis, An Introduction to Atmospheric Thermodynamics, Cambridge University Press, Cambridge, UK, 2002.

[29] A. Akuoko-Asibey, L. C. Nkemdirim, and D. L. Draper, "The impacts of climatic variables on seasonal water consumption in Calgary, Alberta," Canadian Water Resources Journal, vol. 18, no. 2, pp. 107-116, 1993.

[30] R. Sarker, S. Gato-Trinidad, and M. Imteaz, "Temperature and rainfall thresholds corresponding to water consumption in Greater Melbourne, Australia," in Proceedings of the 20th International Congress on Modelling and Simulation (MODSIM2013), Adelaide, Australia, 2013. 